Res., Soc. Dev. 2019; 8(1):e2181567

ISSN 2525-3409 | DOI: http://dx.doi.org/10.33448/rsd-v8i1.567

\title{
Um estudo da possibilidade da minimização da evasão na educação a distância apoiada por terapia alternativa
}

A study of the possibility of evasion minimization in distance education supported by alternative therapy

Un estudio de la posibilidad de minimizar la evasión en la educación a distancia apoyada por terapia alternativa

Cláudio Boghi

ORCID: https://orcid.org/0000-0002-7974-6416

Universidade Anhembi Morumbi, Brasil

E-mail: cboghi@anhembimorumbi.edu.br

Ricardo Shitsuka

ORCID: https://orcid.org/0000-0003-2630-1541

Universidade Federal de Itajubá, Brasil

E-mail: ricardoshitsuka@unifei.edu.br

Dorlivete Moreira Shitsuka

ORCID: https://orcid.org/0000-0002-3282-4843

Universidade Cruzeiro do Sul, Brasil

E-mail: dorlivetems@gmail.com

Recebido: 10/07/2018 - Aceito: 20/08/2018

\section{Resumo}

A Educação a Distância $(\mathrm{EaD})$ é uma modalidade educacional na qual há um alto índice de evasão. Esta pode ser causada por diversos fatores e um deles é a depressão. A diminuição deste fator pode contribuir para a minimização da evasão nesta modalidade. Acredita-se que as terapias alternativas de baixo custo e não medicamentosas possam ser úteis neste tipo de dificuldade. Este artigo tem como objetivo apresentar um estudo que procurar desvelar a possibilidade de emprego de terapia alternativa não medicamentosa. Realiza-se um estudo no qual se faz emprego de terapia por meio de uma mídia social. O estudo trata-se de uma pesquisa social que ocorreu no primeiro semestre de 2017, com 5 participantes, que em princípio estavam com problemas que os levariam a desistir de seus cursos EaD. Os participantes da pesquisa foram tratados no primeiro semestre de 2017. Quatro não desistiram do curso. Os resultados apontaram no sentido de que a terapia alternativa mostrou-se eficaz na 
diminuição do uso de antidepressivos, melhoria na sensação de bem-estar e por conseguinte na diminuição da evasão.

Palavras-chave: Terapia Energética; Depressão; Medicina Integrativa; Educação a Distância.

\begin{abstract}
Distance Education (EaD) is an educational modality in which there is a high level of avoidance. Several factors can cause evasion and one of them is depression. The decrease of this factor can contribute to the minimization of evasion in this modality. We believe that low-cost and non-drug alternative therapies may be useful in this type of difficulty. This article aims to present a study that seeks to unveil the possibility of non - drug alternative therapy. We carried a study in which one makes use of therapy through social media. The study is a social research that occurred in the first half of 2017 , with 5 participants, who in principle had problems that would lead them to give up their EaD courses. We treated research participants in the first half of 2017. Four did not give up the course. The results indicated that alternative therapy shown to be effective in decreasing the use of antidepressants, improving the sense of well-being and therefore reducing avoidance.
\end{abstract}

Key words: Energy Therapy; Depression; Integrative Medicine; Distance Education.

\title{
Resumen
}

La Educación a Distancia (EaD) es una modalidad educativa en la que hay un alto índice de evasión. Esta puede ser causada por diversos factores y uno de ellos es la depresión. La disminución de este factor puede contribuir a la minimización de la evasión en esta modalidad. Se cree que las terapias alternativas de bajo costo y no medicamentosas pueden ser útiles en este tipo de dificultad. Este artículo tiene como objetivo presentar un estudio que busca desvelar la posibilidad de empleo de terapia alternativa no medicamentosa. Se realiza un estudio en el que se hace empleo de terapia por medio de un medio social. El estudio se trata de una investigación social que ocurrió en el primer semestre de 2017, con 5 participantes, que en principio estaban con problemas que los llevarían a desistir de sus cursos EaD. Los participantes de la investigación fueron tratados en el primer semestre de 2017. Cuatro no desistieron del curso. Los resultados apuntaron en el sentido de que la terapia alternativa resultó eficaz en la disminución del uso de antidepresivos, mejora en la sensación de bienestar y por consiguiente en la disminución de la evasión.

Palabras clave: Terapia Energética; depresión; Medicina integral; Educación a distancia. 


\section{INTRODUÇÃO}

A depressão afeta mais de 120 milhões de pessoas no mundo, se caracterizando como o segundo problema mental mais comum. Essa moléstia é apontada como sendo um dos fatores que podem fazer com que um estudante desista de um curso em particular dos cursos da Educação a Distância (EAD). Almeida (2008), Almeida et al. (2013) e Bridi (2016) cujos estudos consideram que a depressão é um fator presente em seus estudos e que pode contribuir para evasão escolar na EAD.

Normalmente, os fatores que levam à depressão são externos aos cursos e ambientes escolares e, podem estar relacionados à perda de um familiar ou amizade, de emprego, desilusão amorosa, discussões ou até mesmo pela falta de contato social. A depressão pode ser um fator que pode levar os estudantes à diminuição do contato social e à evasão escolar. Acredita-se que o contato social, mesmo por meios eletrônicos associado às terapias alternativas possam ser úteis em processos de minimização de seus efeitos. De modo paralelo, Werhmuller e Silveira (2012) ao comparar o Facebook, o Redu e o Orkut consideram que as redes sociais podem apoiar os processos educacionais de modo acessível na educação a distância.

Boghi, Xavier e Faria (2018) estudam uma terapia alternativa, denomina Johrei a distância, que pode ser ministrada por meio de rede social e que ajuda a minimizar o uso de medicamentos, ajuda a melhorar a condição geral das pessoas com depressão e problemas semelhantes e, torna-se interessante investigar se o emprego de uma rede social com terapia alternativa de baixo custo pode ajudar a minimizar o estresse e a depressão das pessoas e desta forma contribuir para uma linha de pesquisa na qual se diminua a evasão escolar.

O objetivo do presente artigo é apresentar uma terapia alternativa de baixo custo aplicada à distância, por meio de rede social e, verificar se ela pode contribuir para a minimização do estresse e depressão e maximização do bem-estar das pessoas.

As terapias medicamentosas, geralmente, são caras, dispendiosas e podem afetar o desempenho das pessoas atendidas por deixá-las sonolentas ou com movimentos alentecidos. Para Herman (2013), há estudos que analisam um impacto econômico-financeiro das terapias integrativas na redução dos custos hospitalares e farmacológicos de uma forma geral. Estas terapias podem se tornar particularmente interessantes para apoiar a diminuição do estresse, depressão dos segmentos sociais que podem se beneficiar desta abordagem. Nas linhas seguintes apresenta-se os conceitos de Medicina Integrativa e Energética como complementar e alternativa aos tratamentos convencionais. 


\section{MEDICINA INTEGRATIVA E ENERGÉGICA}

O paradigma médico convencional é baseado essencialmente em processos bioquímicos, medicação alopática e procedimentos invasivos como métodos de intervenção e manutenção da saúde. Em contrapartida ao paradigma convencional existe o paradigma holístico e integrativo. Esta abordagem valoriza os avanços da medicina moderna, mas concomitantemente considera os aspectos relevantes da medicina complementar e alternativa, que inclui os sistemas médicos orientais e as terapias energéticas.

As pessoas possuem além do aspecto físico do corpo, os aspectos emocionais e psicossomáticos que podem ser considerados na abordagem que considera as pessoas como um todo de modo mais amplo, com corpo, mente e alma. A medicina integrativa enfatiza a necessidade de observar os diversos aspectos que interferem na saúde de uma pessoa: incluindo corpo, mente e espírito. Além de enfatizar que não é apenas o médico ou terapeuta que fornece a cura, esta é fruto também da participação ativa do paciente por meio de prática de exercícios físicos regulares, dietas e outras práticas auxiliares. Atuando nas esferas biológica, psicológica, social, e espiritual relacionadas à doença e ao processo de cura. Dessa forma, acredita-se que a medicina integrativa possa combinar os tratamentos de medicina convencional com tratamentos não convencionais e até holísticos, facilitando a recuperação das pessoas.

As técnicas não convencionais utilizadas em medicina integrativa podem ser divididas em duas categorias: produtos naturais e práticas de mente e corpo. As técnicas baseadas em produtos naturais utilizam substâncias encontradas na natureza, como ervas, vitaminas, minerais, geralmente em uma dosagem diferentes daquelas utilizadas em medicina convencional e são consideradas suplementos alimentares e não drogas. A abordagem nas práticas de mente e corpo envolve o uso de técnicas que afetam, ou atuam, no estado mental, nas funções corporais e nos sintomas dos usuários desses métodos. Dentre os exemplos dessas técnicas estão a meditação, a quiropraxia, a massoterapia, e a medicina energética.

Segundo Benor (2002), o termo medicina energética surgiu a partir da percepção e da crença de terapeutas e pacientes na existência de energias biológicas sutis que permeiam e englobam o corpo humano. Acredita-se que essas energias podem ser acessadas de várias formas por diferentes práticas de medicina complementar e alternativa para fins de diagnóstico e terapias. Já para Gronowicz et al. (2016) a medicina energética é um dos domínios da medicina integrativa que foca na capacidade do biocampo humano promover o 
bem-estar e a saúde. $\mathrm{O}$ conceito do biocampo humano na medicina energética tem suas raízes em diferentes culturas ancestrais que desenvolveram diversas modalidades de terapias como por exemplo, gigong, do-in, pranayama, medicina ayurvédica, kudalini yoga, entre outras. Entretanto, apenas recentemente a ciência ocidental começou a avaliar o potencial e os benefícios dessas terapias.

O Centro Nacional de Medicina Complementar e Alternativa dos Estados Unidos (NCCAM) divide as modalidades de medicina energética em duas classes principais. As modalidades da primeira classe, são categorizadas como modalidades de energia verdadeira (ou verificável), usam campos eletromagnéticos que podem ser mensuradas por meio de tecnologias convencionais, como, eletrocardiograma, eletroencefalograma, e ressonância magnética nuclear, um exemplo de terapia desta modalidade é a eletro-acupuntura.

As da segunda classe, são denominadas de modalidades putativas (ou sutis), pois estas manipulam energias do corpo humano que não podem ser mensuradas pela ciência e tecnologia corrente. Esta segunda classe é também denominada energia de biocampo e buscam afetar os campos energéticos que envolvem e penetram o corpo humano, por meio da aplicação de pressões no corpo, manipulação de partes específicas do mesmo e imposição de mãos como, por exemplo, Reiki, Johrei, passes espirituais e outras técnicas de energia sutil.

\section{JOHREI A DISTANCIA (JD)}

Embora existam tratamentos alopáticos consolidados na literatura médica para o tratamento da depressão mas que fornecem alguma porcentagem de probabilidade de cura, considera-se que nem todos pacientes que recebem estes tratamentos obtém uma cura ou um bem-estar prolongado e desta forma, acredita-se que as terapias alternativas como é o caso do $J \mathrm{D}$ podem ajudar a minimizar as dificuldades dos pacientes.

Para compreender o JD que é ministrado por meio de rede social, torna-se interessante compreender alguns fatos e bases relacionados à essa terapia alternativa: o início ocorre com Mokiti Okada (MK), cujo nome religioso é Meishu-Sama. Este nasceu no dia 23 de dezembro de 1882, no bairro de Hashiba, na cidade de Tóquio, Japão. Esse religioso, desde sua infância, dedicou-se às artes e se preocupava com os problemas da humanidade (GUEDES TERROR, 2009). Trata-se de uma personalidade com viéses religiosos, filosóficos e sociais que trouxe uma influência sobre um segmento da sociedade. Para o IMMB (2004) o legado de MK foi ensinar à humanidade o Johrei que é entendido como sendo a purificação do espírito pela Luz de Divina e que, qualquer pessoa é capaz de transmitir o que considera como sendo a 
"Poderosa Luz de Deus", que purifica o corpo e o espírito e elimina a verdadeira causa de todos os sofrimentos humanos, trazendo saúde, paz e prosperidade ao mundo, conhecido pelo nome de Johrei.

A origem semântica da palavra em foco vem da junção das palavras japonesas: $J o h=$ Purificar, $R e i=$ Espírito, logo para Meishu-Sama, toda a origem da doença física está no espírito. Consiste em um método de canalização de energia por meio de uma medalha chamada Ohikari, outorgada pela Igreja Messiânica Mundial. A transmissão desta energia é feita por meio da imposição de mãos pelo ministrante. Para Meishu-Sama (2017) Johrei irradia alguma forma de onda que ajuda na cura das pessoas.

A energia do Johrei atua limpando o corpo físico e o espírito, purificando-os. Durante a aplicação da técnica, dores e sofrimentos são vistos como formas de purificação física ou espiritual; dessa forma, o receptor do Johrei, ao invés de se lamuriar, deve adotar uma postura de gratidão, entendendo-os como manifestação da "graça divina". Desta forma, na perspectiva deste trabalho, o JD é caracterizado como uma terapia energética, em que, o ministrante realiza a imposição de mãos remotamente para aplicação da técnica.

Essa terapia acessível, sem custos, tem se constituído em uma grande ajuda aos pacientes de doenças crônicas ou terminais. Constitui-se também na abordagem espiritual onde os indivíduos tendem a aproximar-se dos valores e crenças para alívio de grandes dores ou perdas, ou enfrentamento de situações não esperadas. Nesta perspectiva o JD nos pacientes com depressão se apresenta, além uma terapia não farmacológica, como um lenitivo espiritual, pois no horário estipulado, tanto o ministrante do $J \mathrm{D}$ quanto os pacientes estão em sintonia com a espiritualidade, colaborando para o bem-estar dos pacientes e melhorando a receptividade dos mesmos a esta terapia energética. Acredita-se que essa condição de bemestar e autoconfiança possam ser úteis em situações de ensino que envolvam complexidades como é o caso da $\mathrm{EaD}$ na qual existe a separação ente quem ensina e quem aprende e, possivelmente devido a essa dificuldade pode ocorrer a evasão escolar como se aborda no item a seguir.

\section{A EVASÃO NA EDUCAÇÃO A DISTÂNCIA (EAD)}

A evasão escolar (EE) na EAD continua sendo uma dificuldade para a modalidade. Para Silva, Lopes e Alberola (2016) consideram que a evasão escolar na EAD é um problema de nível mundial que em determinadas condições pode alcançar níveis superiores a $50 \%$. Torna-se interessante entender a evasão nos cursos superiores EAD que vai de encontro ao 
sucesso dos ingressantes em um curso superior uma vez que os frustra e trazem um sentido de fracasso.

No Brasil, segundo o CENSO.EAD.Br (2016), a EE nos cursos EaD é maior que aquela dos cursos presenciais: em 2015 essa ficou entre 26\% a 50\%, com $40 \%$ das ocorrências nas instituições que oferecem cursos regulamentados totalmente a distância. A elevada EE em um determinado ano, dificulta o trabalho de planejamento das instituições para os anos seguintes que passam a contar com um número variável de alunos que é imprevisível o que dificulta a previsão orçamentária e de custos. Os resultados observados vão ao encontro da avaliação dos motivos para EE na EaD. Para Martins et al. (2013) as três maiores causas para EE são relacionadas a vida do estudante e seu contexto: $39,3 \%$ tem dificuldades em participar dos encontros presenciais, $19,5 \%$ possui problemas pessoais e 16,8\% de saúde.

Pode-se considerar que os problemas pessoais e de saúde podem ser causadores da depressão e desse modo, a porcentagem subiria para: 36,3, ou seja, mais que um terço dos casos o que mostra a relevância das formas de se minimizar os problemas de depressão.

\section{MÉTODOS}

Na educação superior, como considera Severino (2016) é interessante que ocorra além do ensino, a pesquisa e a extensão. Pesquisa se vale de procedimentos sistemáticos. Uma pesquisa visa obtenção de novos saberes. Como consideram Ludke e André (2013) uma pesquisa exploratória é um estudo inicial visando a obtenção de saber necessário para a realização de estudos posteriores mais completos e aprofundados. Realiza-se uma pesquisa exploratória na qual se busca saber se há influência das terapias alternativas, no caso, a terapia do johrei em relação à possibilidade de redução da evasão na educação a distância.

No presente estudo, realiza-se uma pesquisa qualitativa com pequeno viés quantitativo mas sem o emprego de critérios estatísticos rígidos como ocorre em estudos semelhantes como o de Boghi, Xavier e Faria (2018) mas que contava com uma finalidade diferente, não havendo a preocupação com a questão educacional da evasão escolar e sua minimização. Nesta pesquisa, os participantes deste experimento foram selecionados por meio de uma página da mídia social Facebook, denominada, "Projeto de Pesquisa Científica Baseada no Johrei". Todos os participantes tinham de 17 até 80 anos e possuíam diversos níveis de depressão e concordaram com o termo consentimento de pesquisa livre e assistida.

O grupo de participantes que era de 104 pessoas, destas, 28 participantes formaram o grupo de controle, ou seja, não receberam $J \mathrm{D}$ e 76 receberam a terapia durante o período de 


\section{Res., Soc. Dev. 2019; 8(1):e2181567}

ISSN 2525-3409 | DOI: http://dx.doi.org/10.33448/rsd-v8i1.567

01/10/2016 a 30/04/2017, totalizando 6 meses de tratamento. Por questões éticas e de respeito ao pedido dos envolvidos, evitou-se citar nomes e localidades.

Para o estudo da redução dos antidepressivos e da sensação de bem-estar foram selecionados, além dos 28 pertencentes ao grupo de controle, 40 participantes, dos 76 que receberam Johrei, que sofriam de depressão por mais de 9 meses e recebiam intervenção medicamentosa de antidepressivos.

A escolha desse grupo de 40 participantes foi feita por questões de confiabilidade do estudo e aderência estatística. Foi optado alocar a este grupo, apenas aqueles que sofriam da doença por um período suficiente para que a mesma e o medicamento usado para tratá-la tivessem um efeito estatisticamente significativo na saúde dos participantes. Por se tratar de uma pesquisa exploratória inicial, para coleta de dados fez-se uso de questões simples do tipo sim ou não, sem a preocupação de aprofundamentos nesta fase dos estudos. Observa-se que dos participantes da pesquisa que receberam o $J \mathrm{D}, 5$ estudavam em cursos EaD e também que o conceito de chance é diferente daquele de probabilidade. Na linguagem popular corrente do cotidiano, "chance" tem um sentido semelhante ao de "probabilidade", mas sem uma definição formal. Já probabilidade possui uma definição matemática formal.

\section{RESULTADOS E DISCUSSÃO}

O experimento foi dividido em duas partes, em que o fator de exposição em ambas foi a aplicação do Johrei a Distância (JD). Na Tab. 1, o evento de interesse foi a Redução de antidepressivos e a declaração de bem-estar.

Tabela 1

Johrei a Distância x Redução de Medicamentos

\begin{tabular}{llccr}
\hline Johre & \multicolumn{3}{c}{ Redução } & de \\
$\boldsymbol{i}$ Dist. & \multicolumn{3}{c}{ Medicamentos } \\
\hline & & S & N & Totai \\
& im & ão & & \\
Sim & 9 & & 1 & $\mathbf{4 0}$ \\
& & & 2 & \\
Não & & 35 & & $\mathbf{2 8}$
\end{tabular}


Res., Soc. Dev. 2019; 8(1):e2181567

ISSN 2525-3409 | DOI: http://dx.doi.org/10.33448/rsd-v8i1.567

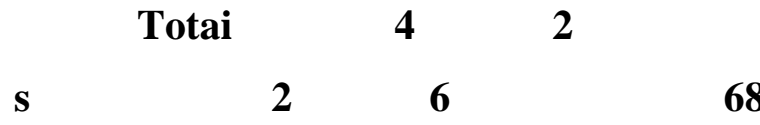

Fonte: dados da pesquisa.

Conforme Tabela 1, das 40 pessoas que faziam uso de medicação e receberam $J \mathrm{D}, 39$ pessoas reduziram a ingestão de medicamentos e uma não. Dos 28 "pacientes" de que não receberam $J \mathrm{D}$ apenas 3 apresentaram redução no uso da medicação. Desta forma, de um total de 68 participantes, 42 pessoas que reduziram medicação e 26 não apresentaram redução. Nos estudos de biocampo relatadas nas literaturas tais como: Reiki, Passe Espírita, Toque Terapêutico entre outras, tem demostrado efetividade na redução da ansiedade, dores e depressão. A redução da depressão e melhoria do bem-estar foram relatados em participantes que receberam $J \mathrm{D}$ no horário e dia estipulado durante os 6 meses de terapia. O Johrei é considerado uma transmissão de energia imediata que é canalizada através da mão do emissor (ministrante) e enviada para um receptor a uma distância média de $30 \mathrm{~cm}$, conforme estabelecido pelas práticas da Igreja Messiânica Mundial.

O $J \mathrm{D}$ proposto por este trabalho também se caracteriza por uma transmissão imediata de energia pela palma da mão de um ministrante direcionada a um receptor, entretanto esta técnica não é limitada por questões espaciais, ou seja, o receptor não necessita estar próximo do ministrante. Os participantes que receberam $J \mathrm{D}$ reportaram um aumento na sensação de bem-estar e uma redução no uso da medicação após a terapia.

A redução dos níveis de depressão e aumento de bem-estar apontam para a efetividade do JD conforme visto nas Tabelas 1 e 2 . A homeostase e os circuitos neuroendócrinos envolvidos na depressão podem ser melhorados pela recepção das terapias de bio-campo. Embora este estudo não tenha focado nos efeitos bioquímicos da recepção do $J \mathrm{D}$ nos participantes, os autores deste trabalho acreditam que esta terapia específica pode ter um efeito positivo nos processos homeostáticos e na circuitaria neuroendócrina. Não foi considerado no estudo aspectos de gênero, faixa etária e religião. Porém observou-se que a maioria dos participantes são da religião messiânica e que já conhece o Johrei tradicional e se interessaram pela técnica do $J \mathrm{D}$.

Este trabalho possui limitações como, uma análise dos aspectos bioquímicos envolvidos na aplicação do $J \mathrm{D}$, utilização de métricas padronizadas da literatura médica para realizar uma análise mais profunda dos resultados obtidos. Além disso, este trabalho poderia ser realizado num contexto clínico hospitalar o que promoveria um redesenho do estudo realizado para a análise de aspectos terapêuticos e práticas médicas que não foram delineadas 
no estudo corrente. Em relação à EaD, constatou-se que 5 dos participantes que possuíam problemas pessoais e/ou de saúde que levaram à considerar-se com depressão e, que na época estudavam em algum curso superior EaD. Para estes, perguntou-se se a depressão poderia fazer com que desistissem do curso. A resposta foi unanimemente afirmativa mostrando que a depressão pode influenciar na desistência em relação ao curso.

A seguir, perguntou-se se após a terapia alternativa, ainda iam desistir do curso. Em quatro dos casos, a resposta foi negativa ou seja, continuariam estudando. Somente um dos casos correspondeu à desistência e se tratava de um estudante que perdeu o emprego e estava passando por dificuldades financeiras que o obrigariam a desistir dos estudos. Perguntados se o $J \mathrm{D}$ os ajudou a prosseguir nos estudos houve as seguintes declarações:

Amostra 1 "Se eu não tivesse participado $J \mathrm{D}$, eu teria desistido de estudar, pois a pressão era muito grande e eu me encontrava desorientada e não entendia as matérias e nem conseguia falar com a tutora e colegas do curso. O JD é feito por meio do Facebook e não custa nada. Só depois que comecei a participar é que melhorei, consegui acompanhar as matérias".

Análise: Verifica-se que há um sentido que relação, por um lado, entre depressão e evasão e este vai ao encontro das colocações realizadas pelos autores Almeida (2008), Almeida et al. (2013) e Bridi (2016). A aluna apresentava dificuldades em organizar a percepção, conceitos e pensamentos na cognição. Por outro lado, a terapia alternativa do $J \mathrm{D}$ ao que tudo leva crer, ajuda a aluna a se tornar mais estável a ponto de permitir que se incentivasse a organizar sua mente e poder prosseguir nos estudos. Essa declaração é semelhante a mais outras duas e por este motivo evitou-se transcrevê-las. Um fator que torna esta terapia alternativa interessante é o fato dela ocorrer na rede social, no caso, o Facebook e como consideram Werhmuller e Silveira (2012) a rede pode apoiar a EaD de muitas formas. Outra declaração foi:

Amostra 2 "Eu queria prosseguir no curso mas enquanto não encontrar um novo emprego, acho que é melhor parar senão as despesas vão aumentando e sinto-me envergonhada".

Análise: Uma das causas de depressão é relacionada à perda do emprego como foi mencionado anteriormente. Neste caso, a estudante fez a terapia alternativa provavelmente pelo fato dela ser gratuita e sem custos em relação a outras terapias que são de custo elevado como considera Herman (2013).

Nem sempre as terapias resolvem todos os problemas, mas ao fortalecer a mente da estudante, pode contribuir para que ela consiga se organizar e se motivar em buscar uma nova 
colocação ao invés de ficar deprimida e sem resolver seus problemas.

Amostra 3 "Fazendo a terapia, ganhei coragem para mudar de curso. Pedi transferência para outro curso EAD e agora sim, estou feliz".

Comentário: Observa-se que o estudante superou algumas dificuldades pessoais que o levavam à imobilidade e à "zona do conforto". Tudo leva crer que por meio da terapia alternativa do $J \mathrm{D}$, o rapaz organizou seus pensamentos e encontrou incentivo para mudar o curso e melhorar sua vida.

A realização de conclusões é muito difícil uma vez que a amostragem foi pequena, desta forma, sugere-se para trabalhos futuros a possibilidade da realização de estudos com uma quantidade maior de participantes bem como o emprego de critérios estatísticos rígidos por meio da realização de estudos quantitativos associados aos qualitativos para obter mais relações e conclusões em relação a associação com a modalidade de educação a distância. Sugere-se também que se realizem estudos com outras terapias alternativas e de baixo custo que possam apoiar as melhorias das condições educacionais e a diminuição em qualquer modalildade.

\section{CONSIDERAÇÕES FINAIS}

O presente artigo contribui com a sociedade mostrando que é possível minimizar os problemas gerados pela depressão e maximizar o bem-estar das pessoas por meio de alternativas como é o caso do Johrei a distância e por conseguinte, melhorar suas atividades incluindo os estudos e possivelmente a evasão escolar em modalidade educacional também a distância.

Neste artigo se apresentou um estudo da verificação da eficácia do Johrei a Distância, por meio de uma mídia social para redução de sintomas de depressão. O resultado do estudo sugere que o JD reduziu o uso de medicamentos e aumentou o bem-estar das pessoas envolvidas o que denota esta terapia como uma prática de medicina integrativa eficaz para o tratamento não farmacológico dos sintomas da depressão. Pode-se constatar também que o uso de uma terapia remota gerou resultados similares aos obtidos pelas terapias energéticas presenciais descritas nas literaturas. Verificou-se também a existência de estudantes de EAD que afirmaram que teriam desistido de seus cursos caso não fizessem a terapia alternativa. Tudo leva crer que ela ajuda na organização da cognição e no incentivo a prosseguir nos estudos e na vida.

Para trabalhos futuros, os autores sugerem um estudo sobre o impacto econômico- 
financeiro do JD nas práticas médicas hospitalares do Sistema de Saúde Brasileiro, tendo em vista que as práticas integrativas em saúde estão sendo incentivadas pelos órgãos responsáveis nacionais e internacionais. Outra sugestão é que se realizem estudos com amostragens maiores e critérios estatísticos para verificar melhor influência da terapia alternativa na evasão e também de outros casos de estudantes de EAD com outros tipos de dificuldades psicossociais que possam levar os estudantes da EAD a evadir de seus cursos. Também se sugere que se realizem estudos com outros tipos de terapias que sejam de baixo custo e de fácil empregabilidade e que possam ser úteis na minimização da evasão escolar de modo a melhorar de alguma forma a educação brasileira e mundial.

Os autores agradecem ao apoio realizado pelo Grupo de Pesquisas MEAC para realização dos estudos e pesquisas.

\section{REFERÊNCIAS}

ALMEIDA, O. C. S. et al. Evasão em cursos a distância: fatores influenciadores. Rev. bras. orientac. prof, São Paulo , v. 14, n. 1, p. 19-33, jun. 2013 . Disponível em: $<$ http://pepsic.bvsalud.org/scielo.php?script=sci_arttext\&pid=S1679-

$33902013000100004 \& \operatorname{lng}=$ pt\&nrm=iso>. Acesso em 11 julho 2018.

ALMEIDA, O. C. S. Evasão em cursos a distância: análise dos motivos de desistência. In: Congresso da Associação Brasileira de Educação a Distância (ABED) 2008. Disponível em: <http://www.abed.org.br/congresso2008/tc/552008112738pm.pdf>. Acesso em: 10 julho 2018.

BALDWIN, A. L.; HAMMERSCHLAG, R. Biofield-based Therapies: A Systematic Review of Physiological Effects on Practitioners During Healing. EXPLORE: The Journal of Science and Healing, v. 10, n. 3, p. 150 - 161, Maio-Junho 2014.

BELMAKER, R. H.; AGAM, G. Major depressive disorder. The new england journal of medicine, v. 358, p. 55-68, Janeiro 2008.

BENOR, D. J. Energy medicine for the internist. Medical Clinics of North America, v. 86, n. 1, p. 105 - 125, Janeiro 2002. ISSN 0025-7125.

BOGHI, C.; XAVIER, R.S.; FARIA, M.M. Johrei a Distância com Suporte de Mídia Social: uma terapia não farmacológica complementar para o tratamento dos sintomas da depressão. Revista Eletrônica do Centro Universitário São Camilo. Edição abril 2018. Disponível em: <https://www.researchgate.net/publication/325768099_Johrei_a_Distancia_com_Suporte_de_ Midia_Social_uma_terapia_nao_farmacologica_complementar_para_o_tratamento_dos_sinto 
mas_da_depressao>. Acesso em: 11 julho 2018.

BRASIL. Ministério da Saúde. Cad. de Atenção Domiciliar. Brasílis, 2013.

BRIDI, L. G. R. Engagement, stress, depressão e ansiedade em alunos de uma escola pública na Bahia - Brasil. Dissertação (Mestrado) apresentada à Faculdade de Psicologia e de Ciências da Educação da Universidade do Porto, orientada pela Professora Doutora Cristina Queirós (FPCEUP), 2016.

BROOKS, A. J. et al. The effect of Johrei healing on substance abuse recovery: a pilot study. Journal of Alternative and Complementary Medicine, v. 12, n. 7, p. 625-631, Setembro 2006. ISSN 1075-5535.

BRUNA, A. Educação formal, não formal e informal: da trilogia aos cruzamentos, dos hibridismos a outros contributos. Mediações - Revista OnLine da Escola Superior de Educação do Instituto Politécnico de Setúbal. v. 2, n. 2, p. 10-25, 2014. Disponível em: $<$ http://mediacoes.ese.ips.pt/index.php/mediacoesonline/article/view/68>. Acesso em: 11 julho 2018.

CALDEIRA, S.; GOMES, A. C.; FREDERICO, M. De um novo paradigma na gestão dos enfermeiros - a espiritualidade no local de trabalho. Revista de Enfermagem Referência, p. 25-35, 2011.

Censo EAD.BR: Relatório Analítico da Aprendizagem a Distância no Brasil 2015 = Censo EAD.BR: Analytic Report of Distance Learning in Brazil 2015. ABED - Ass. Bras.de Educação a Distância. Curitiba: InterSaberes, 2016.

COONEY, G.; DWAN, K.; MEAD, G. Exercise for depression. JAMA, v. 311, p. 24322433, Junho 2014.

CRUWYS, T. et al. Depression and social identity. Personality and Social Psychology Review, v. 18, n. 3, p. 215-238, Abril 2014.

DEL PORTO, J. A. Conceito e diagnóstico. Revista Brasileira de Psiquiatria, 21, n. Suplemento 1, maio 1999. 06-11.

ESPERIDIÃO-ANTONIO, C. M. M. D. E. A. Neurobiologia das emoções. Revista de Psiquiatria Clínica, São Paulo, v. 35, p. 55-65, 2008.

GRONOWICZ, G. et al. Human biofield therapy does not affect tumor size but modulates immune responses in a mouse model for breast cancer. Journal of Integrative Medicine, v. 14, n. 5, p. 389-399, Setembro 2016.

HERMAN, P. M. Evaluating the Economics of Complementary and Integrative Medicine. Glob. Adv Health Med, Seattle, Washington, v.2, n.2, p.56-63, 2013.

IMMB. Igreja Messianica Mundial do Brasil. Curso de formação de membros. São Paulo: 
Fundação Mokiti Okada, 2004.

LIBÂNEO, J. C. Pedagogia e pedagogos para quê? 12ed. SP: Cortez, 2010.

LIMA, P. D. T. Medicina integrativa: a cura pelo equilíbrio. $2^{a}$. ed. São Paulo : MG Editores, 2009.

LUDKE, M.; ANDRE, M. E. D. A. Pesquisa em educação: uma abordagem qualitativa. São Paulo: E.P.U., 2013.

MIWA, M. J. Com o poder nas mãos: um estudo sobre johrei e reiki. Ribeirão Preto: Universidade de São Paulo, 2012.

RELMAN, A. S. Holistic Medicine. New England Journal of Medicine, New England, v. 300, n. 6, p. 312-313, Fevereiro 1979.

RINDFLEISCH, J. A. Biofield Therapies: Energy Medicine and Primary Care. Primary Care: Clinics in Office Practice, v. 37, n. 1, p. 165 - 179, Março 2010. ISSN 0095-4543.

SANTOS, J. M. C. G.; LOPES, P. Q. Teoria quântica e terapia vibracional, uma nova visão a ser inserida nas práticas integrativas complementares: uma revisão da literatura. Revista Saúde Quântica, SP, v.5, n.5, p.142-175, 2016.

SELLI, L.; ALVES, J. D. S. O cuidado espiritual ao paciente terminal no exercício da enfermagem e a participação da bioética. Bioethikos - Centro Universitário São Camilo, p. 43-52, 2007.

SEVERINO, A. J. Metodologia do trabalho científico. 24ed. SP: Cortez, 2016.

SILVA, M. A.D.; LOPES, L. C. V.; ALBEROLA, R. C. S. Análise da importância destinada à evasão nos cursos a distância pelos pesquisadores brasileiros. Paidea - Rev. Cient. de Educação a Distância. v. 8, n. 13, 2016. Disponível em: $<$ http://periodicos.unimesvirtual.com.br/index.php?journal=paideia\&page=issue\&op=view \&p ath[]=83>. Acesso em: 11 julho 2018.

TABATABAE, A. E. A. Effect od Trerapeutic Touch in Patients with Cancer: a Literature Review. Journal of the Academy of Medical Sciences in Bosnia and Herzegovina, abril 2016. 142-147.

TEODORO, W. L. G. Depressão: Corpo, Mente e Alma. Uberlândia: [s.n.], 2010.

VENTEGODT, S.; ANDERSEN, N. J.; MERRICK, J. Holistic Medicine: Scientific Challenges. The Scientific World JOURNAL, v. 3, p. 1108-1116, 2003.

WEHRMULLER, C. M.; SILVEIRA, I. F. Redes sociais como ferramentas de apoio à educação. Rencima, v. 3, n. 3, p. 594-605, 2012. Disponível em: <http://revistapos.cruzeirodosul.edu.br/index.php/rencima/article/viewFile/522/446>. Acesso em: 10 julho 2018. 


\section{Res., Soc. Dev. 2019; 8(1):e2181567}

ISSN 2525-3409 | DOI: http://dx.doi.org/10.33448/rsd-v8i1.567

YIN, R. K. O estudo de caso. 2. ed. Porto Alegre: Bookman, 2015.

YUSSMAN, S. M.; SAHLER, O. J. Z.; LILJEQUIST, K. Complementary and Integrative.

In: LEVESQUE, R. J. R. Encyclopedia of Adolescence. [S.1.]: Springer International Publishing, 2016. p. 1-10. 